\title{
Element Composition, Total Phenolics and Antioxidant Activity of Wild and Cultivated Blackberry (Rubus fruticosus L.) Fruits and Leaves during the Harvest Time
}

\author{
Noémi KOCZKA ${ }^{1 *}$, Éva STEFANOVITS-BÁNYAI ${ }^{2}$, Enikő PROKAJ ${ }^{1}$ \\ ${ }^{1}$ Szent István University, Faculty of Agricultural and Environmental Sciences, Páter K. Street 1, 2100 Gödölló, \\ Hungary;koczka.noemi@mkk.szie.hu (*correspondingauthor);prokaj.eniko@mkk.szie.hu \\ ${ }^{2}$ Szent István University, Faculty of Food Science, Villányi Street 29-43, 1118 Budapest, Hungary; banyai.eva@etk.szie.hu
}

\begin{abstract}
In Europe, blackberry (Rubus fruticosus L.) fruits are cultivated for fresh or processed products, and the leaves are collected for medicinal uses mainly from wild-grown populations. In this study, mineral composition, total phenolic content (FolinCiocalteu's method), and total antioxidant capacity (ferric reducing ability of plasma, FRAP) of blackberries were determined during the harvest period. Leaves and fruits were harvested from wild-grown and cultivated plants at the same locations. Results showed that sampling time and growing place influenced the element composition. Concentration of $\mathrm{Ca}, \mathrm{Fe}, \mathrm{K}, \mathrm{Mg}, \mathrm{P}$, $\mathrm{Zn}$ was significantly higher in cultivated fruits, however, content of $\mathrm{Al}, \mathrm{Cu}, \mathrm{Mn}$ was higher in wild-grown samples. Total phenolic content (TPC) and FRAP values in the leaves increased slightly during the vegetation period. Fruits were harvested at the same maturity stage, their TPC and FRAP level were not influenced by the harvest time. TPC and FRAP levels were higher in blackberry fruits than that in leaves. Significant differences were obtained for TPC and FRAP between wild and cultivated plants, both parameters were higher in the cultivated blackberries. Positive linear correlation was found between the TPC results of wild and cultivated blackberry leaves and fruits, and the same was true for FRAP values. Between TPC and FRAP also a strong positive relationship was observed both in leaves and fruits. Our findings suggest that cultivated blackberry fruits had higher mineral level and antioxidant properties than the wild ones; however, the antioxidant power of leaves from wild populations was similar to that of cultivated plants.
\end{abstract}

Keywords: antioxidant capacity; FRAP; medicinal plant; mineral content; total phenolics

\section{Introduction}

Berry fruits are well-known for their various healthpromoting properties like strengthening the immune system and antioxidant, anti-carcinogenic, antiinflammatory, vasodilatory and antimicrobial effects (Bobinaité et al., 2012; Seeram, 2012). The most significant health benefits of berries are attributed to the phenolic compounds, such as flavonoids, phenolic acids and tannins (Paredes-Lopez et al., 2010; Lee et al., 2012). Fruits with a high phenolic content, including berries serve as natural functional products with considerable health-promoting effect (Szajdek and Borowska, 2008; Nile and Park, 2014).

Blackberries (Rubus fruticosus L.) are widespread in northern countries of the world. Cultivated blackberry fruits have become increasingly popular due to their good taste, high dietary and health values. Among berry fruits, blackberry is considered to be an excellent source of phenolic compounds and vitamins, but also a valuable source of minerals and dietary fibre (Zia-Ul-Haq et al., 2014). Fruits are consumed fresh or as processed products such as jams, jellies, syrups and wines. Blackberries have been found to contain a wide range of bioactive compounds in their fruits such as vitamin C, phenolic acids, ellagitannins, flavonoids including anthocyanins and carotenoids are widely available (Tavares et al., 2013). Blackberry fruits have different pharmacological activities like anticancer, antimicrobial, antioxidant, anti-dysentery, antidiabetic, and antidiarrheal (Dai et al., 2007; Bowen-Forbes et al., 2010). The fruit and juice are also taken for anaemia. A standard infusion made, which can also be applied externally as a lotion, reported to cure psoriasis and scaly conditions of the skin (Piwowarski et al., 2011). Blackberry leaves also have high levels of antioxidants, according to findings of some authors (Buricová et al., 2011; Oszmianski et al., 2015). The 
564

leaves are reported to be used in traditional medicine as antibacterial, anti-inflammatory, anti-diarrhoeic, anti-diabetic and anti-viral agents (Ferlemi and Lamari, 2016).

Total phenolics of blackberry fruits have been extensively studied for a long time. Previous studies demonstrated that level and composition of bioactive compounds (e.g. flavonoids, total phenolics, and acids) in blackberry depended mainly on the genotype. Siriwoharn $e t$ al. (2004), Pantelidis et al. (2007), Kostecka-Gugala et al. (2015), Gündogdu et al. (2016) obtained significant differences among various blackberry cultivars in ascorbic acid, phenolic content, and antioxidant capacity. Yilmaz et al. (2009), Milivojevic et al. (2011) reported higher values for total phenolics and antioxidant capacity in wild-grown blackberry fruits than in cultivated ones. The biochemical composition of blackberries is also influenced by several other conditions such as climate factors (e.g. light intensity, temperature) and agro-technical conditions (e.g. soil, maturity grade). Effect of abiotic circumstances on fruit quality, especially on functional compounds of blackberry was also proved by earlier findings. Reyes-Carmona et al. (2005) evaluated anthocyanins, total phenolics and antioxidant capacity of blackberry fruit extracts originated from different climatic regions. Ali et al. (2012) investigated the influence of nutrition strategy on the bioactive compound levels (e.g. sugars, vitamin C, phenolics, anthocyanins) in blackberry. Mineral concentrations of the fruit are dependably reported in database of U.S. Department of Agriculture, Agricultural Research Service (USDA-ARS, 2016).

Less study focused on phenolic compounds, antioxidant activity or element composition of blackberry leaves. Oszmianski et al. (2015) observed great differences in total phenolics and antioxidant power of leaves of several wild Rubus species. Buricová et al. (2011) found high phenolics and antioxidant level in blackberry leaves. Element concentrations were analysed by some authors in polluted areas (Toth et al., 2008; Nujkic et al., 2016), which data cannot compared to that of blackberries collected or cultivated for human consumption in non-polluted regions. Recent study by Konieczynski and Wesolowski (2012) analysed only water-extractable magnesium, manganese and copper in the leaves.

Although numerous literatures aimed to reveal some aspects of functional role of the blackberry, a need for a comprehensive study is unquestionable. Our work aimed to compare the mineral composition, total phenolic content and total antioxidant capacity of leaves and fruits in wild and cultivated blackberries (Rubus fruticosus L.) grown under similar conditions. Further objective included the monitoring of the above quality factors during the whole harvest period.

\section{Materials and Methods}

\section{Biologicalmaterial}

Samples were collected from wild-grown blackberry (Rubus fruticosus L.) and from cultivated blackberry (Rubus fruticosus L. cv. 'Thornfree') at three growing places in Hungary in three consecutive years. The cultivated 'Thornfree' samples were harvested from plantations on the outskirts of three small towns (Agárd /1/, Dány /2/, Gödöllö /3/) and the samples of wild populations were taken from the nearby forests to these towns. Fully developed leaves were collected monthly from June to September, and ripen fruits were harvested at three times during the ripening period from August to September. Triplicated samples were collected randomly from different parts of the blackberry bushes.

\section{Sample preparation}

For analysis of element composition the leaves were airdried at $30{ }^{\circ} \mathrm{C}$, and the fruits were freeze-dried after homogenisation, then all samples were pulverised. Powered samples $(0.2 \mathrm{~g})$ were digested in a mixture of $2 \mathrm{ml} \mathrm{HNO}_{3}$ and $2 \mathrm{ml} \mathrm{H}_{2} \mathrm{O}_{2}$ in a Teflon bomb. The digested samples were diluted with deionised water to a total volume of 10 $\mathrm{ml}$. For determination of total phenolics and antioxidant capacity, water extracts were prepared by addition of $100 \mathrm{ml}$ distilled water to $1 \mathrm{~g}$ of dried leaves or fruits, the infusions were steeped for $24 \mathrm{~h}$ (Pharmacopoea Hungarica, 2004). Extractions were replicated three times. After steeping, extracts were filtered and centrifuged (1300 rpm, $10 \mathrm{~min}$ ), then the supernatants were analysed.

\section{Determination of element concentration}

The following elements were determined by inductively coupled plasma optical emission spectrometry (ICP-OES, IRIS Thermo Jarrel ASH, USA): Al, As, B, Ba, Ca, Cd, Co, $\mathrm{Cr}, \mathrm{Cu}, \mathrm{Fe}, \mathrm{Hg}, \mathrm{K}, \mathrm{Mg}, \mathrm{Mn}, \mathrm{Mo}, \mathrm{Na}, \mathrm{Ni}, \mathrm{P}, \mathrm{Pb}, \mathrm{Se}, \mathrm{Si}, \mathrm{Sr}, \mathrm{Ti}$, $\mathrm{Zn}$. The concentration of the elements is given as $\mathrm{mg} \mathrm{kg}^{-1}$ dry weight (DW).

\section{Determination of total phenolic content}

The amount of total phenolic content (TPC) was evaluated according to the Folin-Ciocalteu's procedure (Singleton and Rossi, 1965). Briefly, $0.05 \mathrm{ml}$ of diluted extract and $0.45 \mathrm{ml}$ water were mixed with $2.5 \mathrm{ml}$ of $1: 10$ diluted Folin-Ciocalteu's phenol reagent, followed by $2 \mathrm{ml}$ of $7.5 \%(\mathrm{w} / \mathrm{v})$ sodium carbonate. After $5 \mathrm{~min}$ at $50{ }^{\circ} \mathrm{C}$, absorbance was measured at $760 \mathrm{~nm}$. TPC was estimated from a standard curve of gallic acid and results expressed as mg gallic acid equivalents (GAE) $100 \mathrm{~g}^{-1} \mathrm{DW}$. For this method chemicals were used from Sigma-Aldrich Chemie (Budapest, Hungary).

\section{Determination of antioxidant activity}

Total antioxidant capacity was determined by the ferric reducing ability of plasma (FRAP) assay (Benzie and Strain, 1996). A sample containing $3 \mathrm{ml}$ of FRAP solution $(0.3 \mathrm{~mol}$ acetate buffer, pH 3.6 containing $10 \mathrm{mmol}$ 2,4,6-tripyridyls-triazine (TPTZ) and $40 \mathrm{mmol} \mathrm{FeCl}_{3} 6 \mathrm{H}_{2} \mathrm{O}$ ) (SigmaAldrich Chemie, Budapest, Hungary) and $100 \mu \mathrm{l}$ of extract was incubated at $37^{\circ} \mathrm{C}$ for $4 \mathrm{~min}$ and the absorbance was measured at $593 \mathrm{~nm}$. An intense blue colour is formed, when the ferric-tripyridyl-triazine $\left(\mathrm{Fe}^{3+}-\mathrm{TPTZ}\right)$ complex is reduced to the ferrous $\left(\mathrm{Fe}^{2+}\right)$ form at $593 \mathrm{~nm}$. A standard solution of $1 \mathrm{mmol} \mathrm{L}$-ascorbic acid (Merck Chemicals Hungary) in distilled water was prepared. The absorbance change was converted into a FRAP value, by relating the change of absorbance at $593 \mathrm{~nm}$ of the test sample to that of the standard solution of L-ascorbic acid (AA) and results were expressed as $\mu \mathrm{mol} \mathrm{AA} \mathrm{g} \mathrm{g}^{-1} \mathrm{DW}$. 


\section{Statistical analysis}

At least three analyses were run for each sample for element content, total phenolics and total antioxidant capacity. Each analysis consisted of triplicate measurements of each sample and data were averaged over the three measurements. Data were treated for multiple comparisons by analysis of variance (ANOVA), followed by the Duncan's Multiple Range test. Data are presented as means \pm standard deviation. Statistical differences between samples were evaluated by unpaired t-test. Relationship between phenolic content and antioxidant capacity was investigated by performing correlation analysis. For correlation analysis between total phenolics, and FRAP respectively, average values for a given location and sampling time were paired in the case of leaves and fruits of wild and cultivated blackberries. All statistical analyses were realised using Microsoft Excel 2007 software.

\section{Results and Discussion}

\section{Element composition}

Mean macro- and microelement concentrations of blackberry leaves and fruits are shown in Figs. 1 and 2. As there were no significant differences among the investigated years in the element content, average values of the three years are summarised. The concentration of $\mathrm{As}, \mathrm{Cd}, \mathrm{Co}, \mathrm{Cr}$, $\mathrm{Hg}, \mathrm{Mo}, \mathrm{Pb}$ and $\mathrm{Se}$ was under the detection limit in each sample. The absence of heavy metals indicates that the investigated samples are free of toxic metals.

Accumulation of most of the elements in the blackberry leaves has risen slightly during the vegetation period. The differences among the sampling times were significant in the case of $\mathrm{Ca}, \mathrm{K}, \mathrm{Mg}$ and $\mathrm{P}$ levels. The highest increase in the element concentrations was obtained for $\mathrm{Ca}$ and $\mathrm{Mg}$, which became greater by 2 -fold at the end of the investigation
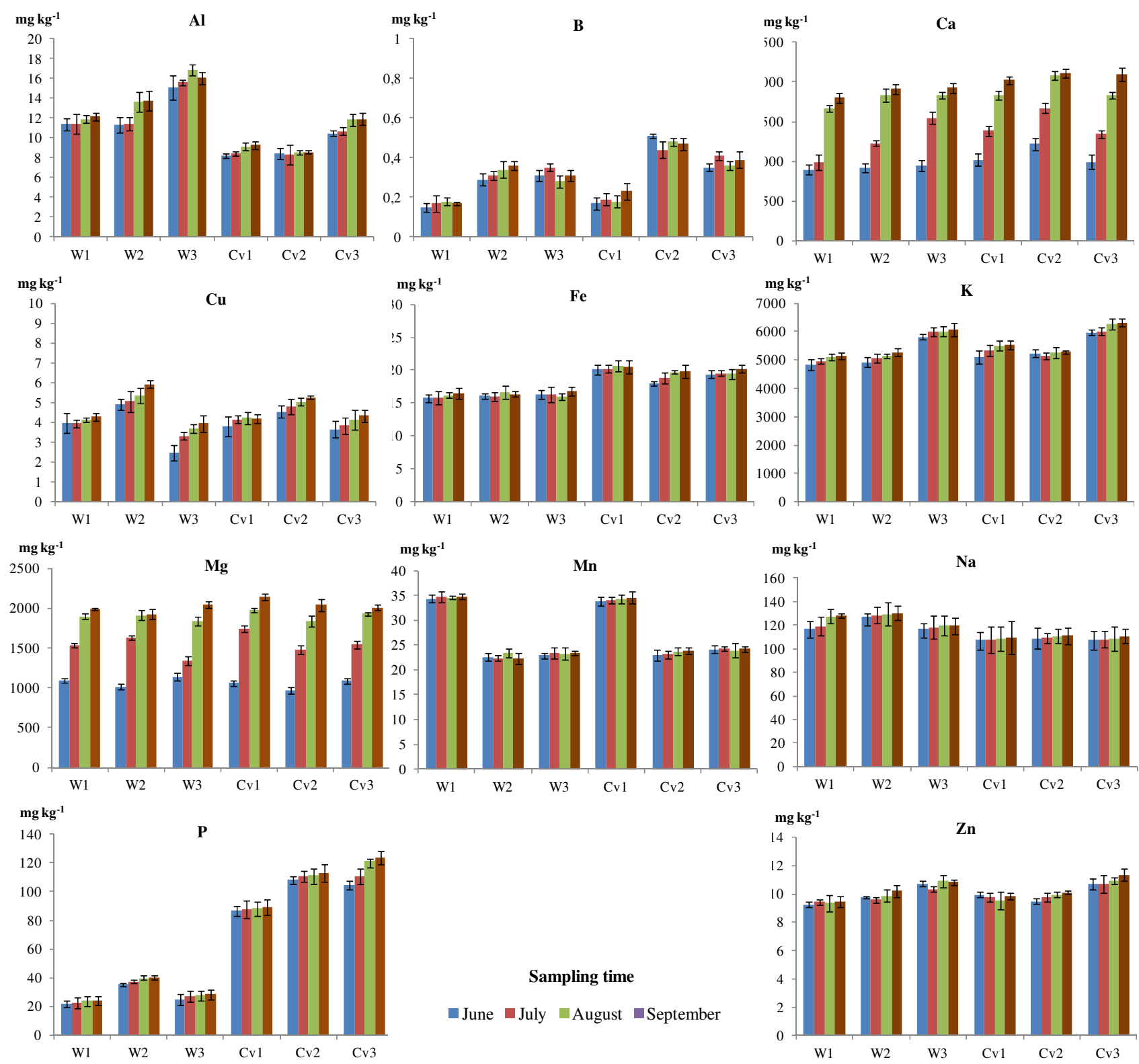

Fig. 1. Element concentrations of wild and cultivated blackberry leaves $\left(\mathrm{mg} \mathrm{kg}^{-1} \mathrm{DW}\right)$ 

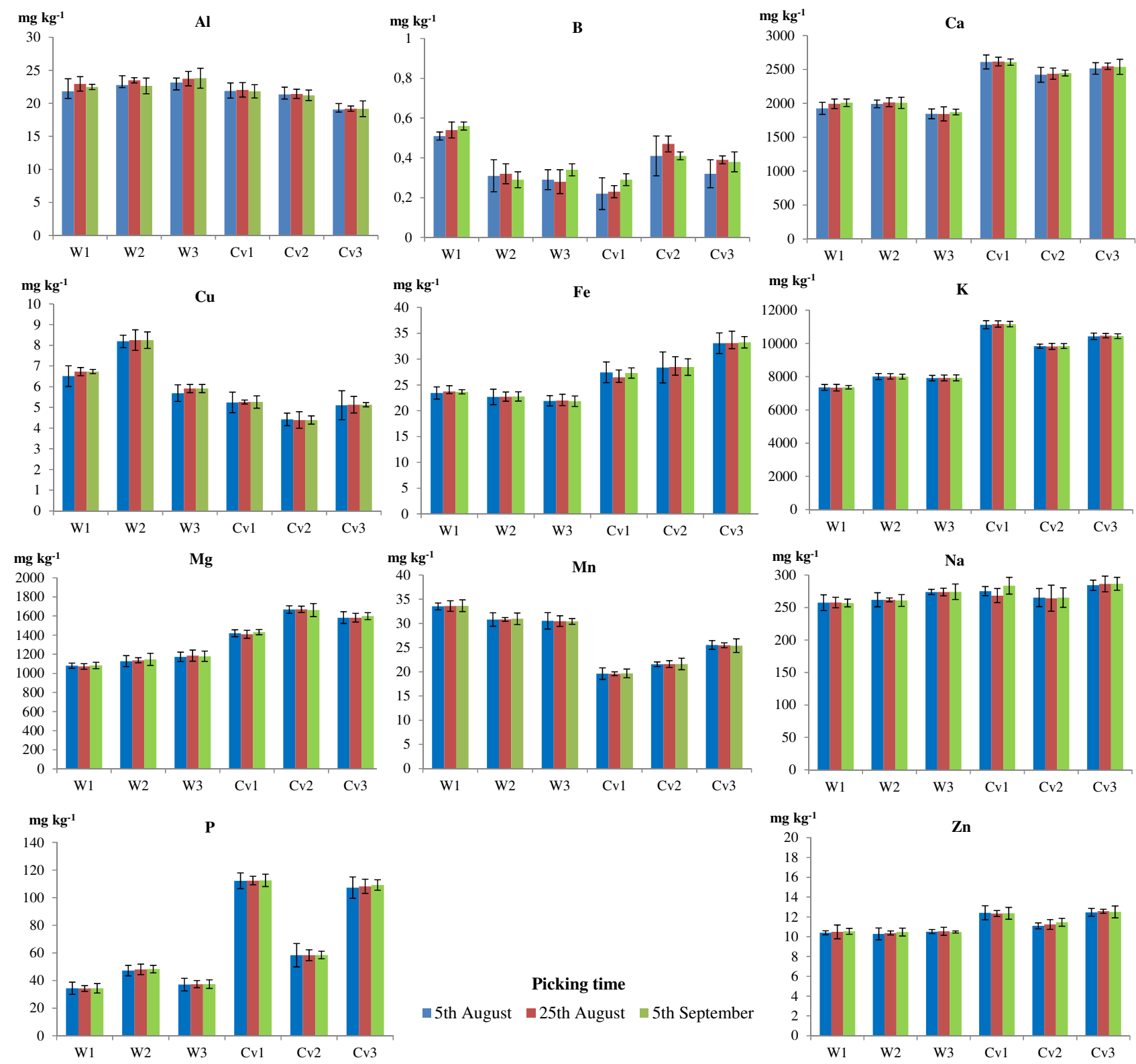

Fig. 2. Element concentrations of wild and cultivated blackberry fruits $\left(\mathrm{mg} \mathrm{kg}^{-1} \mathrm{DW}\right)$

period. Analysing all data, the highest mineral concentration was observed for $\mathrm{K}$. There are not any relevant reports about the element concentrations in blackberry leaves in the literature. However, our results for $\mathrm{Cu}, \mathrm{Mg}$ and $\mathrm{Mn}$ were much lower than found by Konieczynski and Wesolowski (2012), Nujkic et al. (2016), who studied blackberries in polluted areas.

Based on our data, the leaf element composition was influenced by the collection site for $\mathrm{Al}, \mathrm{Cu}, \mathrm{K}, \mathrm{Mn}, \mathrm{Na}, \mathrm{P}$, but for the other elements there were no significant differences among the samples. Comparing wild and cultivated blackberries, significant differences could be detected in the element concentrations of the leaves. Fe and $\mathrm{P}$ contents were higher in cultivated 'Thornfree' samples than in the wild plants. However, $\mathrm{Al}$ content was found to be significantly higher in the wild populations. In case of the other element concentrations, wild and cultivated samples showed similar values.
All blackberry fruits were harvested at the same maturity stage, so there were no differences in their element compositions, they were constant during the picking period. The growing place influenced the accumulation of $\mathrm{Cu}, \mathrm{Mg}$, $\mathrm{Mn}, \mathrm{P}$ in the fruits, however, concentrations of the other elements differed not significantly. Comparing the fruits originated from wild-grown and cultivated populations significant differences were found among the samples. Content of $\mathrm{Ca}, \mathrm{Fe}, \mathrm{K}, \mathrm{Mg}, \mathrm{P}, \mathrm{Zn}$ was higher in cultivated blackberry fruits than in the wild ones, however, $\mathrm{Al}, \mathrm{Cu}$ and Mn concentrations were higher in the wild-grown fruits. The highest element content was detected in the fruits, such as in the leaves, for $\mathrm{K}$.

In the literature, an especially high heterogeneity had been revealed about the element content of blackberry fruits. Similar concentrations to our data were reported for most of the elements by Plessi et al. (2007), USDA-ARS database (2016). Great differences were detected in $\mathrm{Ca}, \mathrm{Mg}$ 
and Fe content to findings of de Souza et al. (2014), who analysed blackberry fruits under climatic and soil conditions differed from those of Europe.

\section{Totalphenolic content}

Total phenolic content of analysed blackberry leaves and fruits are presented in Fig. 3. TPC was high both in leaves and fruits. As shown in Fig. 3 the TPC of leaves has risen during the vegetation period. The differences among the harvest time were significant in most cases. In leaves collected in September a slight decrease was detected, TPC was a little lower at the beginning of autumn than in the summer, although this trend was not statistically verified. Level of TPC in the leaves was mostly similar in samples from the different growing sites. However, significant differences were obtained among the leaf samples from wild and cultivated populations.

TPC values obtained for fruits were significant higher than that for leaves. The level of TPC in fruits measured in this study is generally in good agreement with previously published data (Pantelidis et al., 2007; Zia-Ul-Haq et al., 2014; Cata et al., 2016). Siriwoharn et al. (2004) reported that polyphenol and anthocyanin contents in blackberry fruits were varied at different maturity stages, and found lower TPC levels in ripe fruits than in unripe or overripe ones. In present study, matured blackberry fruits were harvested three times during the ripening period, but no differences were found in TPC either for the sampling times or for the three growing sites. However, significant differences were detected among the wild and the cultivated fruits. The cultivar 'Thornfree' was characterised in samples from every growing place by a significant higher total phenolic content than the fruits picked from wild blackberries. Milivojevic et al. (2011) reported on the contrary significant higher TPC in wild-grown samples, while TPC values both for wild and cultivated blackberry were unusually low. Yilmaz et al. (2009) found that TPC varied greatly among cultivars and selected wild genotypes, characterised by mainly higher values in the wild blackberries, however, differences between cultivated and wild-grown genotypes were lower than obtained in present study. Analysing average values of wild and cultivated populations paired for a given location and sampling time, for the TPC significant positive correlations were found both in leaves $(\mathrm{r}=0.8114, \mathrm{p}<0.01)$, and fruits $(\mathrm{r}=0.7624$, $\mathrm{p}<0.05)$.
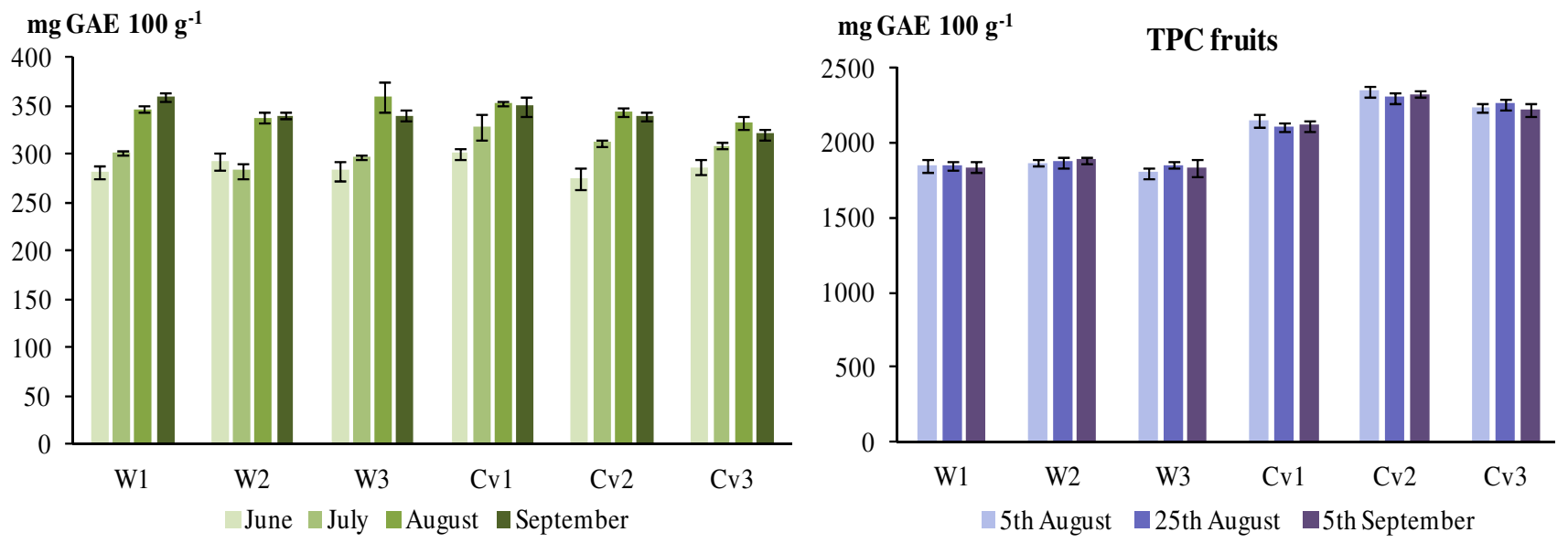

Fig. 3. Total phenol content (TPC) in leaves and fruits of blackberry (mg GAE $\left.100 \mathrm{~g}^{-1} \mathrm{DW}\right)$
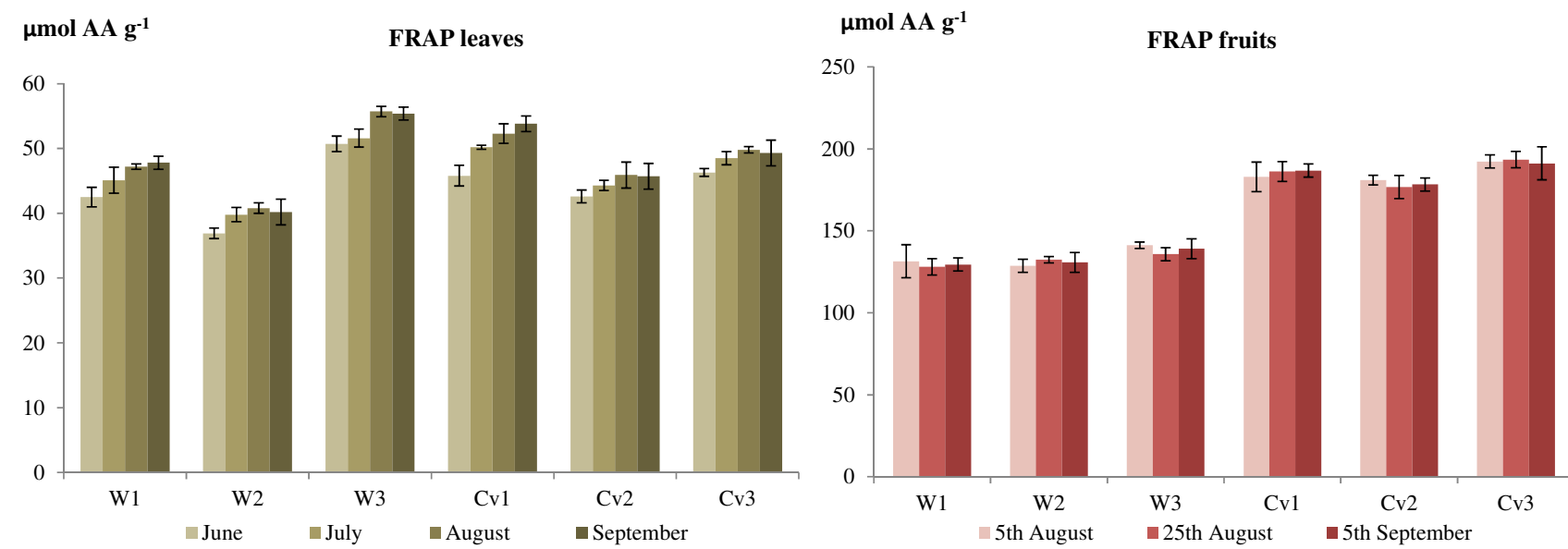

Fig. 4. Antioxidant capacity (FRAP) in leaves and fruits of blackberry ( $\left.\mu \mathrm{mol} \mathrm{AA} \mathrm{g}{ }^{-1} \mathrm{DW}\right)$ 
568

\section{Antioxidant capacity}

Fig. 4 presents the total antioxidant capacity (using FRAP method) of blackberry leaves and fruits. Similarly to TPC, FRAP values estimated for the leaves increased during the harvest time. The same trend was found by Wang and Lin (2000) evaluating antioxidant capacity as oxygen radical absorbance capacity (ORAC). Based on our data, growing place influenced the antioxidant capacity of the leaves. However, marked differences were noticed between wildgrown and cultivated leaf samples originated from the same location, antioxidant power of wild plants were characterised by higher values.

Several different methods are used for determination of antioxidant capacity. Blackberry fruits were studied by many authors for antioxidant power, however, their results cannot be compared directly with each other. Similar ranges for FRAP found in this study were reported by Siriwoharn et al. (2004), Pantelidis et al. (2007). Antioxidant capacity of blackberry fruits was not influenced either by the harvest time or the growing place. On the other hand, comparison of wild-grown and cultivated fruits brought significant differences: FRAP values in the cultivated samples were higher than those in the wild-grown material. Milivojevic et al. (2011) observed higher antioxidant capacity in wild blackberry fruits using the ABTS (2,2-azino-bis-3ethylbenzothiazoline-6-sulfonic acid) method, while Yilmaz et al. (2009) detected no differences by the radical scavenging activity 2,2-diphenyl-1-picrylhydrazyl radical (DPPH) method. Correlation analysis for the FRAP values resulted significant positive relationships between wild and cultivated samples, both in leaves $(\mathrm{r}=0.6170, \mathrm{p}<0.05)$, and fruits $(r=0.6626, p<0.05)$.

In the literature, for blackberry fruits the correlation between TPC and antioxidant capacity evaluated by different methods is reported (Pantelidis et al., 2007; Milivojevic et al., 2011; Cata et al., 2016). Our results confirmed that FRAP values are related to total phenolics, which relationship was characterised by a high correlation coefficient $(\mathrm{r}=0.9074, \mathrm{p}<0.01)$ in the fruits, and a weaker positive linear correlation $(r=0.4545, p<0.05)$ was found in the leaves.

\section{Conclusions}

In present study, in blackberry leaves concentration of some macro elements, total phenolics and antioxidant capacity assessed by FRAP method increased during the harvest period from June to August. These parameters evaluated in the leaves were influenced less by the growing site, but rather by the genotype variance of wild and cultivated populations. Element content was mostly higher in wild-grown leaf samples, while TPC and FRAP showed higher values in the cultivated 'Thornfree'. In blackberry fruits, no significant differences presented in element composition, TPC or FRAP among the different sampling times, what can be explained by the same maturity stage of harvested fruits. Remarkable differences were obtained between wild-grown and cultivated blackberry fruits in point of mineral concentrations of some macro and micro elements, total phenolics and antioxidant capacity. TPC and FRAP values were higher in the cultivar 'Thornfree' than those in wild fruits samples. Positive linear correlations were observed between TPC and FRAP of wild and cultivated populations both in leaves and fruits. These results showed that cultivated blackberry fruits had higher mineral level and antioxidant power, representing a higher quality for health-promotion than wild blackberries. However, blackberry leaves did not differ in point of antioxidant properties. It can be said, that the expedience of leaves of wild populations as medicinal herb is similar to those of cultivated plants.

\section{Acknowledgements}

This research received no specific grant from any funding agency in the public, commercial, or not-for-profit sectors.

\section{References}

Ali L, Alsanius BW, Rosberg AK, Svensson B, Nielsen T, Olsson ME (2012). Effects of nutrition strategy on the levels of nutrients and bioactive compounds in blackberries. European Food Research and Technology 234:33-44.

Benzie IFF, Strain JJ (1996). Ferric reducing ability of plasma (FRAP) as a measure of antioxidant power: The FRAP assay. Analytical Biochemistry 239(1):70-76.

Bobinaité R, Viskelis P, Venskutonis PR (2012).Variation of total phenolics, anthocyanins, ellagic acid and radical scavenging capacity in various raspberry (Rubus spp.) cultivars. Food Chemistry 132(3):1495-1501.

Bowen-Forbes CS, Zhang Y, Nair MG (2010). Anthocyanin content, antioxidant, anti-inflammatory and anticancer properties of blackberry and raspberry fruits. Journal of Food Composition and Analysis 23(6):554560.

Buricová L, Andjelkovic M, Cermáková A, Réblová Z, Jurcek O, Kolehmainen E, ... Kvasnicka F (2011). Antioxidant capacity and antioxidants of strawberry, blackberry, and raspberry leaves. Czech Journal of Food Sciences 29(2):181-189.

Cata A, Stefanut MN, Pop R, Tanasie C, Mosoarca C, Zamfir AD (2016). Evaluation of antioxidant activities of some small fruits containing anthocyanins using electrochemical and chemical methods. Croatica Chemica Acta 89(1):37-48.

Dai J, Patel JD, Mumper RJ (2007). Characterization of blackberry extract and its antiproliferative and anti-inflammatory properties. Journal of Medicinal Food 10(2):258-265.

De Souza VR, Pereira PAP, Da Silva TLT, De Oliveira Lima LC, Pio R, Queiroz F (2014). Determination of the bioactive compounds, antioxidant activity and chemical composition of Brazilian blackberry, red raspberry, strawberry, blueberry and sweet cherry fruits. Food Chemistry 156:362-368.

Ferlemi AV, Lamari FN (2016). Berry leaves: An alternative source of bioactive natural products of nutritional and medicinal value. Antioxidants5(2):17.

Gündogdu M, Kan T, Canan I (2016). Bioactive and antioxidant characteristics of blackberry cultivars from East Anatolia. Turkish Journal of Agriculture and Forestry 40:344351. 
Konieczynski P, Wesolowski M (2012). Water-extractable magnesium, manganese and copper in leaves and herbs of medicinal plants. Acta PoloniaePharmaceutica-Drug Research 69(1):33-39.

Kostecka-Gugała A, Ledwozyw-Smolen I, Augustynowicz J, Wyzgolik G, Krucze M, Kaszycki P (2015). Antioxidant properties of fruits of raspberry and blackberry grown in central Europe. Open Chemistry 13: 1313-1325.

Lee J, Dossett M, Finn CE (2012). Rubus fruit phenolic research: The good, the bad, and the confusing. Food Chemistry 130:785-796.

Milivojevic J, Maksimovic V, Nikolic M, Bogdanovic J, Maletic R, Milatovic D (2011). Chemical and antioxidant properties of cultivated and wild Fragaria and Rubus berries. Journal of Food Quality 34(1):1-9.

Nile SH, Park SW (2014). Edible berries: Bioactive components and their effect on human health. Nutrition 30(2):134-144.

Nujkic MM, Dimitrijevic MM, Alagic SC, Tosic SB, Petrovic JV (2016). Impact of metallurgical activities on the content of trace elements in the spatial soil and plant parts of Rubus fruticosus L. Environmental Science: Processes \& Impacts 18(3):297-418.

OszmianskiJ, Wojdylo A, Nowicka P, Teleszko M, Cebulak T, Wolanin M (2015).Determination of phenolic compounds and antioxidant activity in leaves from wild Rubusspecies. Molecules 20(3):4951-4966.

Pantelidis GE, Vasilakakis M, Manganaris GA, Diamantidis G (2007). Antioxidant capacity, phenol, anthocyanin, and ascorbic acid contents in raspberries, blackberries, red currants, gooseberries and Cornelian cherries. Food Chemistry 102:777-783.

Paredes-López O, Cervantes-Ceja ML, Vigna-Pérez M, Hernández-Pérez T (2010). Berries: Improving human health and healthy aging, and promoting quality life - A review. Plant Foods for Human Nutrition 65(3):299-308.

Pharmacopoea Hungarica (2004). Medicina Press (8th ed). Budapest.

Piwowarski PJ, Kiss A, Kozłowska-Wojciechowska M (2011). Antihyaluronidase and anti-elastase activity screening of tannin-rich plant materials used in traditional Polish medicine for external treatment of diseases with inflammatory background. Journal of Ethnopharmacology 137(1):937-941.

Plessi M, Bertelli D, Albasini A (2007). Distribution of metals and phenolic compounds as a criterion to evaluate variety of berries and related jams. Food Chemistry 100:419-427.

Reyes-Carmona J, Yousef GG, Martinez-Peniche RA, Lila MA (2005). Antioxidant capacity of fruit extracts of blackberry (Rubus sp.) produced in different climatic regions. Journal of Food Science 70(7):S497-S503.
Seeram NP (2012). Emerging research supporting the positive effects of berries on human health and disease prevention. Journal of Agricultural and Food Chemistry 60(23):5885-5886.

Singleton VL, Rossi JA (1965). Colorimetry of total phenolics with phosphomolybdic phosphotungstic acid reagents. American Journal of Enology and Viticulture 16(3):144158.

Siriwoharn T, Wrolstad RE, Finn CE, Pereira CB (2004). Influence of cultivar, maturity, and sampling on blackberry (Rubus L. hybrids) anthocyanins, polyphenolics, and antioxidant properties. Journal of Agricultural and Food Chemistry 52:8021-8030.

SzajdekA, BorowskaE (2008). Bioactive compounds and health-promoting properties of berry fruits: A review. Plant Foods for Human Nutrition 63(4):147-156.

Tavares L, Figueira I, McDougall GJ, Vieira HL, Stewart D, Alves PM, ... Santos CN (2013). Neuroprotective effects of digested polyphenols from wild blackberry species. European Journal of Nutrition 52:225236.

Toth A, Braun M, Toth Z, Gor D, Lakatos G (2008). Element composition of Rosa canina and Rubusfruticosus fruits at an abandoned metalliferous minesite in N-Hungary. Cereal Research Communications 36(5):1655-1658.

USDA-ARS (2016). US Department of Agriculture, Agricultural Research Service, USDA nutrient database for standard reference, Release 28. Retrieved 2018 February 10 from http://www.nal.usda.gov/ fnic/foodcomp.

Wang SY, Lin HS (2000). Antioxidant activity in fruits and leaves of blackberry, raspberry, and strawberry varies with cultivar and developmental stage. Journal of Agricultural and Food Chemistry 48(2):140-146.

Yilmaz KU, Zengin Y, Ercisli S, Serce S, Gunduz K, Sengul M, Asma BM (2009). Some selected physico-chemical characteristics of wild and cultivated blackberry fruits (Rubus fruticosus L.) from Turkey. Romanian Biotechnological Letters 14(1):4152-4163.

Zia-Ul-Haq M, Riaz M. De Feo V, Jaafar HZE, Moga M (2014). Rubus fruticosus L: Constituents, biological activities and health related uses. Molecules 19(8):10998-11029. 